Bolpagni M., Burdi L., and Ciribini A. L. C. (2017). "The Implementation of Building Information Modelling and Lean Construction in Design Firms in Massachusetts and its Correlation with Client's Requirements." In: LC3 2017 Volume II - Proceedings of the 25th Annual Conference of the International Group for Lean Construction (IGLC), Walsh, K., Sacks, R., Brilakis, I. (eds.), Heraklion, Greece, pp. 235242. DOI: https://doi.org/10.24928/2017/0310

\title{
THE IMPLEMENTATION OF BUILDING INFORMATION MODELLING AND LEAN CONSTRUCTION IN DESIGN FIRMS IN MASSACHUSETTS
}

\author{
Marzia Bolpagni ${ }^{1}$, Luciana Burdi ${ }^{2}$, and Angelo Luigi Camillo Ciribini ${ }^{3}$
}

\begin{abstract}
It is not easy to evaluate Building Information Modelling (BIM) and Lean Construction (Lean) capabilities of design firms. The paper investigates the level of BIM and Lean implementation at representative design firms in Massachusetts. A survey was given to the principal design firms working for a large public client. First, answers were analysed and discussed. Second, results from the same design firm were compared to detect possible inconsistencies. Main results show that there is still not a clear definition of BIM and Lean; BIM training is not done consistently within design firms; and there is not a common understanding of BIM and Lean within each design firm, even though most designers affirmed that they have internal standards. Results of the survey could be useful for designers to develop internal standards and establish training courses for the design firm and clients to better understand designers' approach to BIM and Lean.
\end{abstract}

Keywords: Building Information Modelling, Lean Construction, Design Firm.

\section{INTRODUCTION}

Building Information Modelling (BIM) can be defined as a set of technologies, processes and policies enabling multiple stakeholders to collaboratively design, construct and operate a facility in virtual space (Succar 2017). BIM deals with the entire life cycle of a facility and all parties involved have to collaboratively work together (Eastman et al. 2011).

In order to maximise profit by maximising efficiency and removing waste of resources, the construction sector has started to adopt the Lean thinking originated in Japanese manufacturing (Asri and Nawi 2015). Lean Construction (also called Lean) refers to the adaptation and application of principles coming from the Toyota Production System to the design and construction process (Sacks et al. 2009). Lean Construction can be defined as a set of new processes that increases the efficiency of construction by providing better value to the client and decreasing waste from the process (Dave 2013). Building Information Modelling and Lean Construction have been separately developed (Sacks et al. 2010). However, they have been recently analysed together (Ahuja et al. 2014; Alarcon et al. 2013; Arayici et al. 2011; Bhatla and Leite 2012; Clemente and Cachadinha 2013; Dave 2013; Dave et al. 2013a; Dave et al. 2013b; Hamdi and Leite 2012; Khan and Tzortzopoulos 2014; Oskouie et al. 2012; Sacks et al. 2010; Sands and Abdelhamid 2012), but there can be a

1 PhD Candidate, Department of Architecture, Built Environment and Construction Engineering, Politecnico di Milano, Milano, Italy, marzia.bolpagni@polimi.it

2 Adjunct Assistant Professor, Department of Civil and Environmental Engineering, Worcester Polytechnic Institute, Worcester, Massachusetts, USA, lburdi@wpi.edu

3 Full Professor, Department of Civil, Environmental, Architectural Engineering and Mathematics, University of Brescia, Brescia, Italy, angelo.ciribini@unibs.it 
strong synergy between Lean and BIM during the whole life cycle of a project (Dave et al. 2013b).

Designers play an important role in the entire design and construction process, however, it is not always easy to evaluate BIM capabilities of design firms. Succar et al. (2013) developed an assessment framework for BIM competency evaluations of individuals and organisations, and several surveys have been carried out in the past (such as the NBS in the UK (2015) and the McGraw-Hill Construction in USA (2012)). However, it is still not easy to determine whether employees of the same design firm have a common understanding of BIM and Lean.

For this reason, the paper investigates the level of BIM and Lean implementation at design firms working for a large client in Massachusetts.

\section{Methodology}

In order to gather empirical data on the current use of BIM and Lean in design firms in Massachusetts, a deductive approach based on an online survey was used. The survey was given to the principal design firms working for a large public client that requires the use of BIM and Lean. Design firms were selected based on their ability to manage a BIM-based process on previous projects. The survey was open to several BIM experts working in the same company (e.g., BIM Directors, BIM Managers, and BIM Specialists). In this way, it was possible to analyse whether employees have a common understanding of BIM and Lean. Survey respondents were contacted via email and a link to the online survey was provided. All questions were closed-ended and SurveyMonkey ${ }^{\odot}$ was selected to manage the online survey. Separate collectors were created for each design firm to compare anonymous answers. The online questionnaire was accessible for three months starting in November 2015.

A total of seven design firms took part to the survey. Nineteen professionals filled out the survey, but only seventeen completed the entire survey. For this reason, only the seventeen completed surveys were analysed.

The survey contained 20 questions covering the following main topics:

- General information

- BIM-based tools

- BIM training sessions

- BIM standards

- BIM and Lean integration

- Model Checking

- Client's requirements on BIM

\section{THE IMPLEMENTATION OF BIM AND LEAN IN DESIGN FIRMS}

This section presents results of the survey. First, all answers are analysed and discussed. Second, results of the same design firm are compared to detect possible inconsistencies.

\subsection{Current use of BIM}

\subsubsection{General Information}

This section included the following questions: 
- What is the size of your company (number of employees)?

- What does BIM mean for your company/organisation?

- How long has your company/organisation been using BIM?

- For which disciplines do you use BIM?

Most of the selected design firms had more than 500 employees (53\%), followed by companies with $11-50(18 \%), 51-100(12 \%)$ or $101-500$ people (12\%). Only one company had less than 10 employees (5\%).

Respondents mainly defined BIM as a methodology that also includes the use of innovative tools (71\%), but some respondents viewed BIM mainly as a tool (technology) $(29 \%)$.

Most of respondents had used BIM for 1-5 years (59\%), followed by 6-10 years (24\%) or less than one year $(12 \%)$. Only a few design firms had more than 10 years of experience $(5 \%)$.

Not all design firms used a complete Building Information Model that included all disciplines. The predominantly developed disciplines of Building Information Models were architecture (88\%) and structure (59\%). Mechanical, electrical and plumbing services (MEP) discipline models also were developed, such as plumbing (41\%), electrical and alarm systems (41\%), mechanical systems (35\%) and fire protection (29\%) (Figure 1).

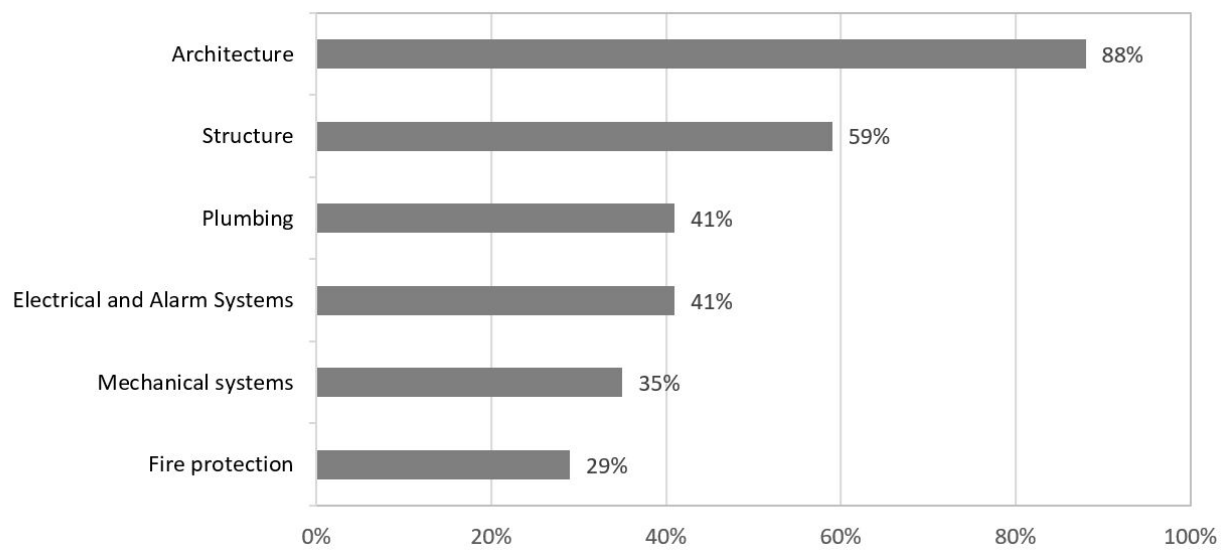

Figure 1: Disciplines of Building Information Models

\subsubsection{BIM-based tools}

This section included the following questions:

- If you do not use BIM internally for all disciplines, how do you select partners with BIM capabilities?

- Which BIM authoring software do you usually use?

- Do you find any limitations in using BIM authoring software in comparison with 2D-based tools?

- What BIM-based analyses do you usually perform?

- Do you find any limitations when performing BIM-based analyses in comparison with traditional tools (e.g., 2D-based tool or manual controls)?

- Do you integrate Laser scanning of existing conditions within a BIM environment?

- $\quad$ Do you use an OpenBIM approach based on open standards (e.g., .IFC or .BCF)? 
Some respondents answered that they internally used Building Information Modelling to create and manage all disciplines (35\%). In situations where the design firm used partners, , the selection of partners was based on both no-BIM requirements such as previous collaboration on other projects (47\%), as well as the presence of BIM experts in the team $(47 \%)$. Other selection criteria included previous collaboration on other BIMbased projects (35\%); the relevance (24\%) and the number (12\%) of BIM-based projects completed by the company; and the relevance of BIM-based projects performed by BIMexperts within the firm.

There was a unanimous agreement among all respondents on the use of Autodesk Revit@ as BIM authoring software. However, more than a half of them (53\%) believed that there are limitations in using such a tool in comparison with 2D-based software.

A list of most common BIM-based analyses was provided to understand their adoption within different design firms. Building Information Models were used to perform several analyses such as clash detection (53\%), daylight and sun studies (47\%), energy analysis (35\%), structural analysis (29\%), lighting analysis (18\%), LEED credit certification reporting (11\%) and mechanical analysis (5\%). Most of respondents (76\%) did not perceive any limitations in using BIM software in comparison with traditional tools or manual controls.

In addition, respondents advised that laser scanning is used by a large number of design firms $(76 \%)$ and is integrated in a BIM environment. On the other hand, an OpenBIM approach based on open standards (e.g., Industry Foundation Classes IFC and BIM Collaboration Format BCF) is not common and only a few (24\%) adopt it.

\subsubsection{BIM training}

This section included the following question:

- How often do you offer BIM training sessions for your staff?

Most of the respondents (35\%) answered that their company offers BIM training to staff once a year. Some respondents answered that their company does not provide any kind of internal training (18\%). Other respondents advised that their firms organise training sessions twice a year (5\%), every three months (5\%), every month (25\%) or more than once a month (12\%).

\subsubsection{BIM standards}

This section included the following question:

- Do you have internal BIM standards?

All respondents answered that their design firms have internal BIM standards and most of those standards address both Building Information Models and BIM-based processes (71\%). A smaller number of design firms had standards to manage only Building Information Models (24\%) or a BIM-based process (5\%).

\subsubsection{Lean implementation}

This section included the following questions:

- How long have you been using Lean Construction?

- Which Lean Construction tools and processes are you using?

The majority of respondents have been using Lean for 1-5 years (65\%); some have used Lean for less than one year (18\%); some do not use Lean at all (12\%). Only a few design 
firms have a longer experience of 6-10 years (5\%). The most common Lean tool used are: Pull Planning (59\%), Choosing by Advantages, (47\%) and A3 Process for Decision Making (41\%). The Lean process of Target Value Design (29\%) is seldom used.

\subsubsection{Model Checking}

Model Checking plays an important part within BIM processes, because it allows quality control of information (geometrical and alphanumeric) within Building Information Models (Ciribini et al. 2015). It can be done visually or using specific tools. In some tools, it is possible to set specific rules (rule-sets) to check Building Information Models against (e.g., to check if the dimension of a particular space is correct). The Model Checking phase is also essential in the Plan-Do-Check-Act process to promote continuous improvement.

The questions included in this section were:

- Which software do you use to perform Model Checking for quality assurance?

- Do you have standard rule-sets to control models (e.g., automatic rules to control dimension of spaces, presence of BIM objects, classification systems)?

- Who performs quality control of models?

Model Checking was mainly performed using Autodesk Navisworks@ (59\%) or the BIM authoring software (35\%). Only one respondent used BIM Assure $\odot$, that supports rule-sets for Model Checking. Some respondents advised that they do not perform Model Checking at all $(18 \%)$.

In addition, 53\% of respondents did not use rule-sets to control models. Only a few had standard rule-sets to control models $(29 \%)$ or they created rule-sets for each project (18\%). It is possible that respondents did not understand this question, because answers were not consistent with previous statements, since even if only one person used a rule-based software (BIM Assure $\odot$ ), more than one respondent has rule-sets to control models.

Often, both designers and an internal BIM manager performed quality controls of models $(82 \%)$; only in few cases were they separately carried out by designers $(12 \%)$ or BIM Managers $(6 \%)$.

\subsubsection{Client's requirements on BIM}

This section included the following questions:

- For how many projects did the owner ask the use of BIM in the last five years?

- For which purposes has BIM been required?

The majority of respondents advised that in the last five years BIM had been required by clients for 1-5 projects (53\%), followed by 6-15 (23\%), 16-30 (18\%), and 51-100 (6\%) projects. The principal required BIM uses were the creation of models for all (65\%) or some disciplines (59\%) and quantity take off (47\%). Other uses included conceptual design studies (e.g., space programming and massing) (29\%), BIM-based analyses (e.g., structural, mechanical, energy, lighting) (23\%), and budgetary costing model (6\%).

\subsection{Understanding of BIM and Lean within the same design firm}

Seven design firms took part to the survey, but only six of them provided more than one answer. For this reason, a comparison was conducted on six companies. Results of the same design firm were compared to find possible dissimilarities and calculate the 
The Implementation of Building Information Modelling and Lean Construction in Design Firms in Massachusetts

percentage of inconsistency. In this way, it was possible to verify whether there is a common understanding on BIM and Lean among experts within the same firm.

Table 1: Percentage of inconsistency of answers for each design firm.

\begin{tabular}{cc}
\hline Design Firm & $\begin{array}{c}\text { \% of } \\
\text { Inconsistency }\end{array}$ \\
\hline B & $89 \%$ \\
C & $72 \%$ \\
E & $72 \%$ \\
G & $50 \%$ \\
F & $44 \%$ \\
D & $28 \%$ \\
\hline
\end{tabular}

Results are included in Table 1 . The values of the percentage of inconsistency varied from $89 \%$ (design firm B) to 28\% (design firm D). The average value was 59\% (Figure 2).

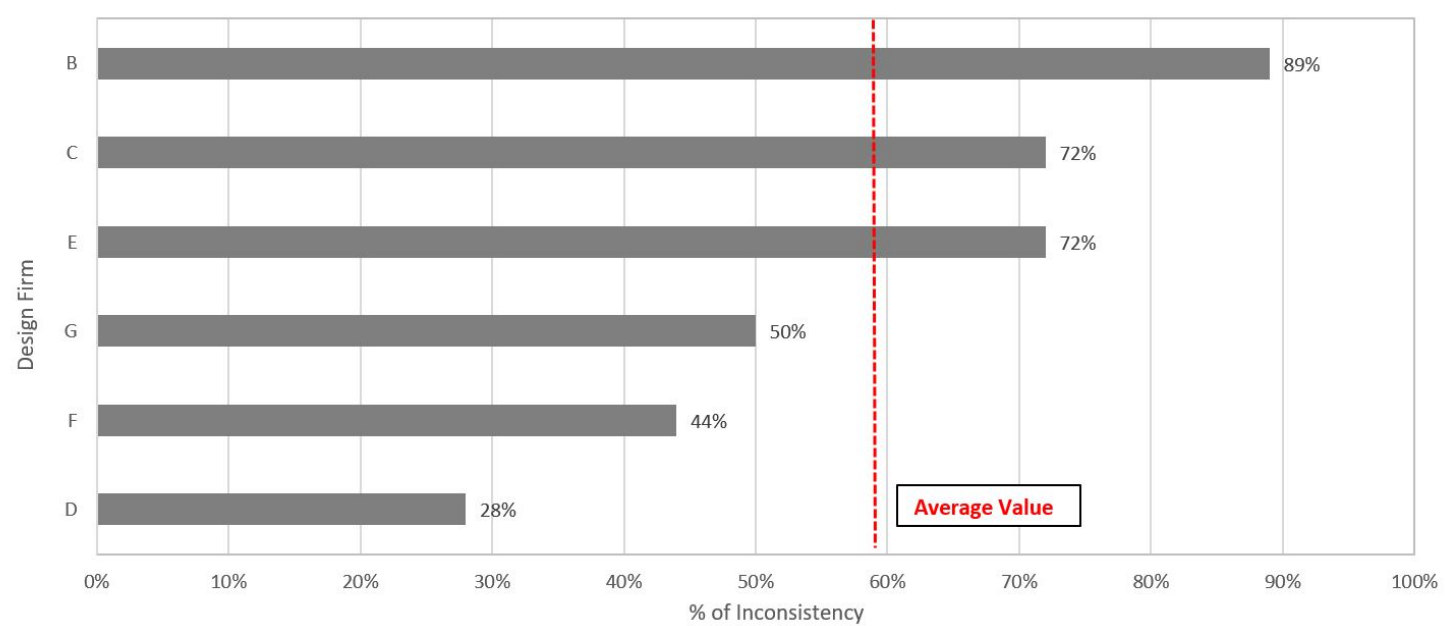

Figure 2: Average value of the percentage of inconsistency

\section{DisCUSSION AND CONCLUSIONS}

Main results show that there is not a clear definition of BIM within design firms, even if BIM standards are established. Not all design firms create Building Information Models for all disciplines; this could be related to firms' scope of services limitations (e.g., some organisations are specialised only on architecture and do not provide structural or MEP models).

BIM and Lean adoption are relatively new and only a limited number of design firms has more than 10 years' experience. Moreover, BIM training is usually provided only once a year and this could lead to heterogeneous views and gaps in understanding of BIM policies. For this reason, training sessions should be scheduled more often to avoid misunderstanding and to promote continuous improvement. 
The use of rule-sets that allow semi-automatic Model Checking is still limited. For this reason, design firms should invest more in the control of their work in order to support a more effective BIM and Lean approach.

It is interesting to note that, when design firms select partners to develop BIMprocesses, often selection criteria do not include BIM capabilities. There is a possibility that this practice is affected by the small number of BIM-based projects previously done by design firms in Massachusetts.

BIM is becoming a mandatory requirement in public works, and clients play an important role as 'data-drivers' (Bolpagni et al. 2016). In Massachusetts, public clients can ask for specific software, in contrast with other areas, such as Europe, where open standards (e.g., Industry Foundation Classes) are preferred requirements. For this reason, in Massachusetts, as well as in other American states, usually proprietary software is specified and open BIM standards are not included in public procurements.

Although the survey results indicate that there is not a univocal understanding of BIM and Lean within the same design firm, inconsistencies in responses show the limitation of surveys. Workshops with more than one BIM/Lean expert from the same organisation could be a valid alternative to surveys in order to get more reliable data.

Results of the study can be useful for designers to develop internal standards and establish internal training programs, as well as for clients to better understand designers' approach to and use of BIM and Lean. Due to the low response rate from the design firms, results cannot be generalised to the entire construction industry. However, the study results can be used by researchers in order to improve data collection methods and to better understand the current status of BIM and Lean implementation in Massachusetts.

In the future, the same questions could be sent to different design firms working with other public clients to compare results and better evaluate the impact of clients' requirements on design firms' behaviours. Finally, other maturity matrices, such as the one developed by Bilal Succar (2010), could be used to evaluate BIM and Lean implementation across design firms.

\section{REFERENCES}

Ahuja, R., Sawhney, A. and Arif, M. (2014). Bim Based Conceptual Framework for Lean and Green Integration. In: Kalsaas, B.T., Koskela, L. and Saurin, T.A., 22nd Annual Conference of the International Group for Lean Construction. Oslo, Norway, 25-27 June 2014, pp. 123-132.

Alarcon, L.F., Mandujano, M.G. and Mourgues, C. (2013). Analysis of the Implementation of VDC from a Lean Perspective: Literature Review. In: Formoso, C.T. and Tzortzopoulos, P., 21th Annual Conference of the International Group for Lean Construction. Fortaleza, Brazil, 31-2 August 2013, pp. 781-790.

Arayici, Y., Coates, P., Koskela, L., Kagioglou, M., Usher, C. and O'Reilly, K. (2011). Technology adoption in the BIM implementation for lean architectural practice. Automation in Construction. 20(2), pp. 189-195.

Asri, M. A. N. M., and Nawi, M. N. M. (2015). Actualizing Lean Construction: Barriers Toward the Implementation. Adv. Environ. Biol., 9(5), pp. 172-174.

Bhatla, A. and Leite, F. (2012). Integration Framework of BIM with the Last Planner System. In: Tommelein, I.D. and Pasquire, C.L., 20th Annual Conference of the International Group for Lean Construction. San Diego, USA, 18-20 July 2012. 
Bolpagni, M., Ciribini, A. and Philp, D. (2016). The European Client's Attitude Towards the Quasi-Automation of the Procurement Processes within a Digital Environment. Proceedings of the CIB World Building Congress 2016. Volume III, pp. 429-439.

Ciribini, A., Mastrolembo Ventura, S. and Bolpagni, M. (2015). Informative content validation is the key to success in a BIM-based project. Territorio Italia, n. 2/2015, pp. 9-30.

Clemente, J., and Cachadinha, N. (2013). BIM-Lean Synergies in the Management on MEP Works in Public Facilities of Intensive Use - a Case Study. In: Formoso, C.T. and Tzortzopoulos, P., 21th Annual Conference of the International Group for Lean Construction. Fortaleza, Brazil, 31-2 August 2013, pp. 751-759.

Dave, B. (2013). Developing a construction management system based on lean construction and Building information modelling. $\mathrm{PhD}$ thesis, University of Salford.

Dave, B., Koskela, L., Kiviniemi, A., Owen, R., Tzortzopoulos, P. (2013). Implementing Lean in construction. Lean construction and BIM. CIRIA.

Eastman, C., Teicholz, P., Sacks, R., and Liston, K. (2011). BIM Handbook: A guide to Building Information Modeling for Owners, Managers, Designers, Engineers and Contractors. 2nd ed. USA: John Wiley \& Sons, Inc.

European Parliament (2014). Directive 2014/24/EU of the European Parliament and of the Council of 26 February 2014 on public procurement and repealing Directive 2004/18/EC.

GSA (2007). BIM Guide 01 - 3D-4D-BIM Overview.

McGraw-Hill Construction, 2012. The Business value of BIM in North America: MultiYear Trend Analysis and User Ratings (2007-2012), Bedford, U.S.

NBS (2015). Building Information Modelling (BIM): Reports from NBS, National Buildings Specification.

Raisbeck, P., Millie, R. and Maher, A. (2010). Assessing integrated project delivery: a comparative analysis of IPD and alliance contracting procurement routes. In: Egbu, C. (Ed), Proceedings 26th Annual ARCOM Conference, 6-8 September 2010, Leeds, UK, Association of Researchers in Construction Management. Vol. 2, pp. 1019-1028.

Sacks, R., Koskela, L., Dave, B. A., and Owen, R. L. (2010). Interaction of Lean and Building Information Modeling in Construction. The Journal of Construction Engineering and Management, 136(9), pp. 968-980, doi: 10.1061/(ASCE)CO.1943-7862.0000203.

Sands, M. and Abdelhamid, T.S. (2012). Whole-Building Measurement and Computing Science BIM for Lean Programming and Performance. In: Tommelein, I.D. and Pasquire, C.L., 20th Annual Conference of the International Group for Lean Construction. San Diego, USA, 18-20 July 2012.

Succar, B. (2010). Building Information Modelling Maturity Matrix. Handbook of research on Building Information Modelling and construction informatics: concepts and technologies, J. Underwood and U. Isikdag, eds., IGI Publishing, pp. 65-103.

Succar, B. (2017). Building Information Modelling (BIM). BIM Dictionary. BIMe. Available at: http://bimdictionary.com/building-information-modelling/ [Accessed 14 Jan. 2017].

Succar, B., Sher, W. and Williams, A. (2013). An integrated approach to BIM competency assessment, acquisition and application. Automation in Construction, 35 (2013), pp. 174-189. 